\title{
THE OLDEST KNOWN FOSSIL INSECT
}

\author{
By D. J. SCOURFIELD, I.S.O.
}

$\mathrm{O}$ N January 18, I gave a detailed account, before the Linnean Society of London, of further specimens of the oldest known fossil insect.

It is still a quite commonly accepted belief that there is no authentic record of fossil insects from rocks earlier than those of the Carboniferous period. Since 1926, however, there has been good reason to believe that insects had at last been found in Devonian strata. In that year Hirst and Maulik ${ }^{1}$ described and figured four heads of a small arthropod, which they named Rhyniella proceursor, and which they considered to belong to the Insecta. (The jaw-like structures also referred to by Hirst and Maulik, and afterwards named Rhyniognatha hirsti by Tillyard, although possibly belonging to a larval insect, cannot seriously be regarded as a definite record of a fossil insect.) These heads had been obtained from the Rhynie Chert, a siliceous deposit of Middle Devonian age, well known to palæobotanists for its beautifully preserved plant remains, and so called because of its occurrence at Rhynie, near Huntly, in Aberdeenshire.

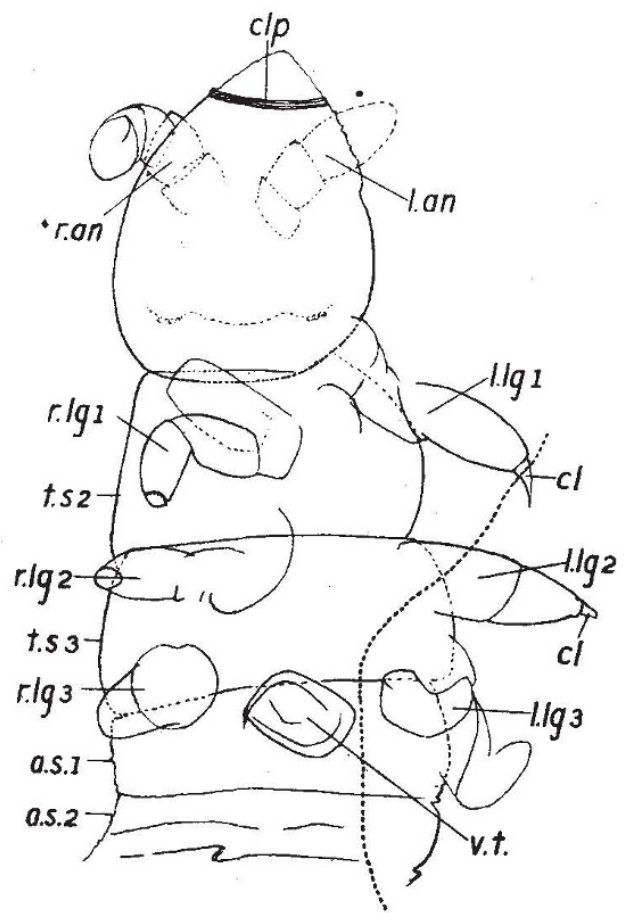

Fig. 1.

HEAD, THORAX AND TWO ABDOMTNAT SEGMENTS: WITH ANTENNA, PORTIONS OF THREE PAIRS OF LEGS, INDICATION OF VenTral TUBE, ETC. DORSI-VENTraL position. Figure ventral. $(\times 105$.

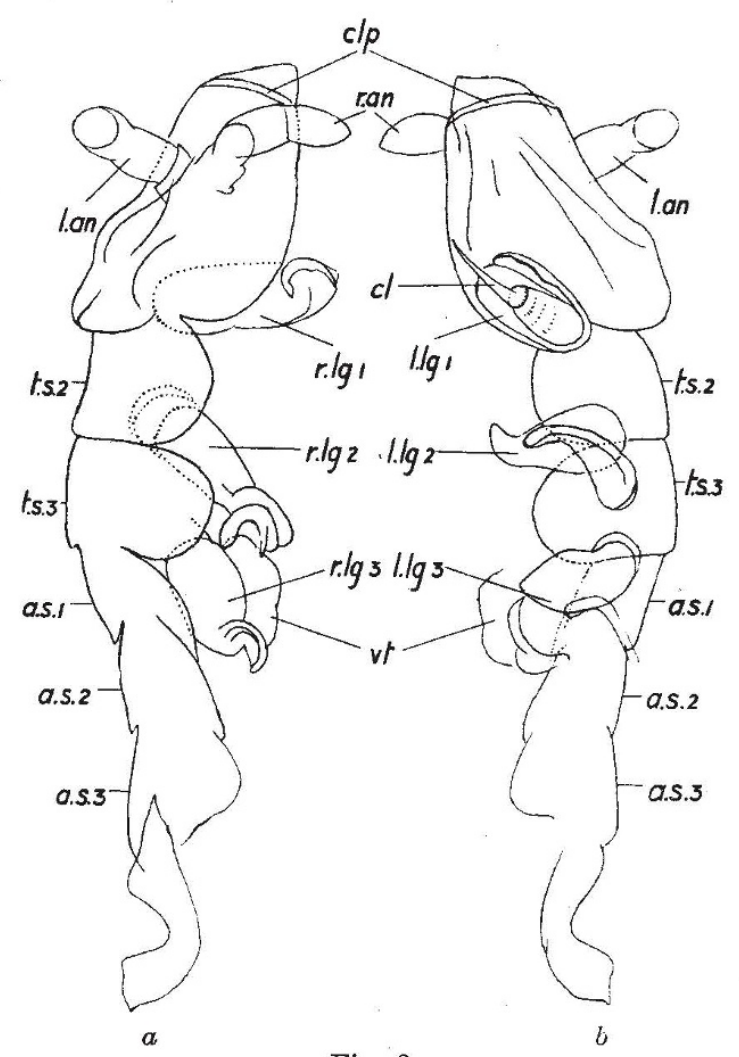

Fig. 2.

Head, thorax aNd THRee abdominal segments : WITH ANTENN $\not E$, THREE PAIRS OF LEGS, ETC. LATERAI position, bUt head nearly dorsi-ventral. ProbABLY A CAST SKIN. $a$ RIGHT SIDE, $b$ LEFT SIDE. $(\times 105$.

It is true that some doubt has been entertained as to whether these heads were really insectan, but the late Dr. R. J. Tillyard ${ }^{2}$, after careful examination of the specimens, was convinced that they belonged to an insect of the order Collembola and might even be of a Podurid type. Coming from such an authority on fossil insects, this spinion seemed pretty conclusive. In view, however, of the great geological antiquity of the Rhynie Chert (some three hundred million years is a modern estimate of the age of the Devonian period $^{3}$ ) there still appeared to be a possibility that such heads might have been attached to bodies differing somewhat from those of any other insects. This, however, has now been shown not to be the case, and it may therefore be confidently said that Rhyniella was a true Collembolan. Since the publication of Hirst and Maulik's 
and Tillyard's papers a number of further specimens of Rhyniella have been found in the same material, mostly by the late Rev. Wm. Cran. These are now in the Geological Department of the British Museum (Natural History), and are described in the current number of the Proceedings of the Linnean Society ${ }^{4}$, from which the accompanying illustrations are reproduced by courtesy of the Council. Three of the new specimens show heads attached to considerable portions of the bodies (Figs. 1 and 2). It will be seen that the body was elongated, with the segments distinct, thus bringing Rhyniella within the suborder Arthropleona. They also show that the first thoracic segment (pro-thorax) was without a welldeveloped tergum, that there were three pairs of legs and that a ventral tube was probably present on the first abdominal segment. No specimen has yet been found with the posterior part of the abdomen intact, and it is impossible to say whether a 'spring' was present or not. The total length of the organism was apparently between $1 \frac{1}{2}$ and $2 \mathrm{~mm}$.

Three additional detached heads have also been found, two of which are represented in the accompanying Figures 3 and 4 . These heads, while fully confirming the collembolan nature of the mandibles, the conclusion drawn by Tillyard from his examination of the original specimens, also indicate that some at least of the other structures to be found within the head of a recent Collembolan (maxillæ, lingua, etc.) were present in Rhyniella, and further that the animal was provided with ocelli comparable with those of many recent forms.

As was pointed out by Tillyard, the antennae of Rhyniella were typically Podurid, but the absence of a tergum on the pro-thorax indicates affinity with the Entomobryidæ, so that the position of the animal would appear to be intermediate between the two families into which the arthropleonid Collembola are usually divided. This, however, is not a point of very much importance. The remarkable fact is that in all essentials Rhyniella was so similar to modern Collembola that, so far as can be seen, it throws

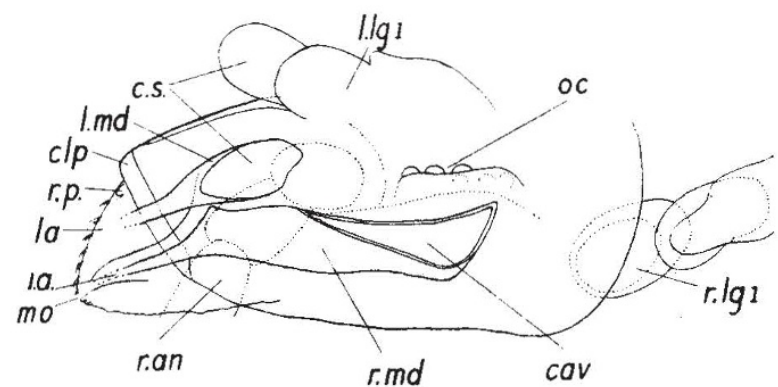

Fig. 3.

HEAD : WITH MANDIBLES, INDICATIONS OF ONE ANTENNA, OCELII, ETC. NEARLX DORSI-VENTRAL POSITION, BUT SLIGHTLY TO ONE SIDE. FIGURE ALMOST VENTRAL. $(\times 130$.

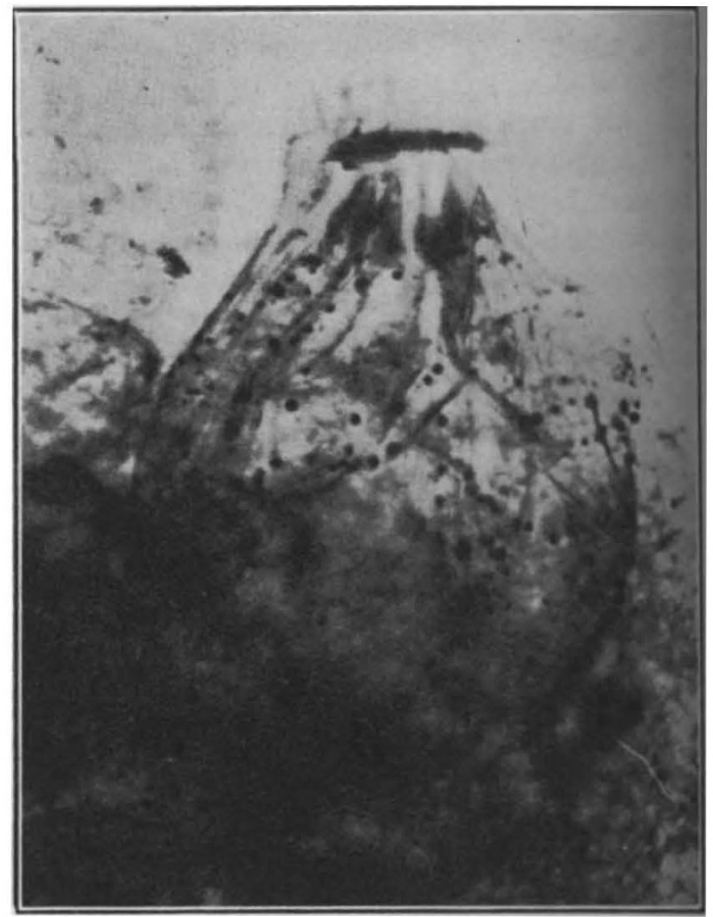

Fig. 4 .

Head : With mandibles, antennat, parts of First PAIR OF LEGS, AND MUCH INTERNAL STRUCTURE OF UNDFTERMINED NATURE (? MAXILLAE, ? LINGUA, ETC.). Dorsi-ventral position. $(\times 200$. $)$

no light even upon the affinities of that group to the other orders of Apterygotan insects, let alone upon the origin of insects generally. What it does certainly show is that the origin of the Collembola, and presumably of Apterygotan insects generally, must have been very much earlier than Middle Devonian.

Fossil Collembola have so far only been found in three very widely separated geological periods. Before the discovery of the Devonian Rhyniella, the only records were from the Baltic amber of Oligocene age, all belonging to existing genera. Quite recently, however, another form has been found in Canadian amber of Cretaceous age. It has been named by Folsom $^{5}$ Protentomobrya walkeri and placed in a new family, Protentomobryidæ, intermediate between the Poduridæ and Entomobryidæ, because of the structure of the anterinæ on one hand and the absence of a pro-thoracic tergum on the other, as in Rhyniella. It is possible, therefore, that the latter should be included in this new family.

In the discussion following the reading of the paper at the Linnean Society various points of general interest were brought out. Dr. K. Jordan said that entomologists had been convinced, by the study of the morphology of recent Aptera, that these were primitive and not, like lice and fleas, late derivations from winged forms, and now 
palæontology has confirmed the conviction and turned an opinion into a fact. Dr. F. E. Zeuner thought that the proved occurrence of a specialized group of Apterygotan insects in Middle Devonian material showed that wingless insects were present before winged insects, and that the appearance of the latter coincided with the first forest vegetation on the earth. The earliest tree-like plants were Middle Devonian and it was conceivable that certain Apterygotan insects, which, however, must have been related to the Thysanura rather than the Collembola, took possession of this new kind of habitat and developed wings from lateral pleuræ of the thorax acting as parachutes. Dr. W. T. Calman pointed out the great interest of the glimpse into past conditions afforded by the fortunate discovery of the Rhynie Chert. Prof. F. E. Weiss directed attention to the fact that whereas the plant remains in the Rhynie Chert are of very primitive land plants not directly comparable to any existing groups, Rhyniella can be related to existing Insecta. Similarly in the Carboniferous period, well-developed insects occur comparable to some existing groups whereas the plants are essentially different from recent plants. There seems, therefore, to be a certain lag in the development of modern forms of plants as compared with insects.

${ }^{1}$ Hirst, S., and Maulik, S., Geol. Mag., 63, 69 (1926).

2 Tillyard, R. J., Trans. Entomol. Soc., 65 (1928).

3 NATURE, 139, 334 (1937).

- Scourfleld, D. J., Proc. Linn. Soc. Lond., April 25, 1940, p. 113.

' Folsom, J. W., Univ. Toronto Studies, Geol. Series, 40 (1937).

\section{Explanation of lettering of Figures.}

$\begin{array}{ll}\text { an. Antenna. } & l g . \text { Leg. } \\ \text { a.s. Abdominal segment. } & \text { mi. Mandible. } \\ \text { cav. Opening to mandible cavity. } & \text { mo. Mouth. } \\ \text { cl. Claw. } & \text { oc. Ocelli. } \\ \text { clp. Clypeus. } & \text { r. Right. } \\ \text { c.s. Cut by section. } & \text { r.p. Rounded projection at base } \\ \begin{array}{ll}\text { i.a. Incisor area of mandible. } & \text { of labrum. } \\ \text { l. Left. } & \text { t.s. Thoracic segment. } \\ \text { la. Labrum. } & \text { v.t. Ventral tube. }\end{array}\end{array}$

\title{
THEORIES OF THE LIQUID STATE
}

\author{
By Prof. N. F. Mott, F.R.S., \\ UNIVERSITY OF BRISTOL
}

\begin{abstract}
A JOINT meeting of the Physical Society and of the Cambridge Philosophical Society was held at Cambridge on April 29 to discuss the properties of liquids. Among other subjects considered were the problem of melting and also the question of how one ought to calculate the viscosity of a simple liquid. It is extraordinary how difficult these problems are and how little progress has been made with them, especially since, if we exclude the quite exceptional case of liquid helium, it seems very unlikely that quantum mechanics has any bearing on the problems; thus all the physical principles necessary for the investigation may well have been available since the time of Clerk Maxwell. It is not so much the difficulty in picturing what happens when a solid melts, as the difficulty in giving mathematical expression to what happens that holds up progress. In fact, all the attempts at exact mathematical treatment start from models which simplify the phenomenon of melting in such a way that some of the essential features are probably lost.
\end{abstract}

The problem of viscosity appears in some ways as the most fundamental, because fluidity is, after all, what distinguishes a liquid from a solid, though the distinction is not absolute, since many solids, metals, for example, show creep at high temperatures under small stresses. Andrade ${ }^{1}$, in 1934 , pointed out that the right order of magnitude for the viscosity could be obtained on the assumption that each successive layer of atoms in the liquid glides over the next, and that each layer transfers all its momentum to the next once in each semi-period of vibration. The vibrational frequencies are taken from the characteristic temperature of the solid, and are assumed to have the same order of magnitude in the liquid. Perhaps the most important advance on this simple theory is that of Eyring ${ }^{2}$, who attempts to account for the temperature dependence of the viscosity. Eyring considers that one layer of atoms glides over another only at places where, owing to statistical fluctuations, the density is abnormally low; he expresses this by saying that 'holes' form in the liquid, and estimates from the temperature variation of the viscosity that the size of a hole is about one third of the volume normally occupied by an atom. This point of view makes an interesting contrast possible with the state of affairs in solids; whereas in liquids only a very small departure from the normal structure is necessary for glide to take place, in solids, according to recent theories, a 'dislocation' must be formed, which is a type of discontinuity with considerable energy extending over many atoms. According to Orowan ${ }^{3}$, creep is due to the thermally activated motion of such dislocations, and the slow creep rates are due to the large energies of activation involved. 